\title{
An Investigation into Practices and Perceptions of Saudi University Learners of English towards Their Dictionaries' Use for Learning Purposes
}

\author{
Sultan Samah A Almjlad \\ Lecturer of Linguistics and Translation, Department of English Language \\ Northern Borders University, Arar, Saudi Arabia \\ E-mail: sultan8778@hotmail
}

Received: March 16, 2017 Accepted: April 10, 2017 Published: April 16, 2017

doi:10.5296/ijele.v5i1.11072 URL: https://doi.org/10.5296/ijele.v5i1.11072

\begin{abstract}
This study investigates the dictionary use practices of Saudi students. Twenty Saudi postgraduate students from both genders (12 males and 8 females) participated in the study. All participants were postgraduate students at the University of Salford in the UK. Questionnaire and interview were the instruments used to collect data. The study discovered a number of results regarding the research questions. The findings indicated that most of the Saudi learners used their dictionaries for finding the meaning of the target words followed by checking the pronunciation of the same word. The study discovered three serious problems that face Saudi EFL learners while using their dictionaries namely the difficulty in understanding the phonetic symbols, difficulty of finding the correct words and, in addition, insufficiency of illustrative examples given in the dictionary. Moreover, the study explored that the Arabic bilingual dictionary was the single most preferred dictionary in its paper format for their educational purposes. The study concluded with emphasising the prime importance of training in dictionary use, indicating that most of the Saudi learners did not receive any form of training on the use of dictionary.
\end{abstract}

Keywords: Dictionary use, dictionary difficulties, dictionary types, Saudi EFL learner, training 


\section{Ml Macrothink}

\section{Introduction}

The dictionary is an active tool in learning any foreign language and it plays a significant role in this field. Li (1998), in her study, referred to the key role of dictionary use in learning a foreign language indicating that dictionaries are among the most effective and main books in both native language acquisition and in foreign language learning as well. The EFL learners, in learning a foreign language, need to increase their linguistic storage in the target language which is, in Saudi Arabia, the English Language. The EFL learners who possess a wide knowledge of vocabulary can comprehend, communicate and guarantee that the process of language acquisition will be flexible and successful. The knowledge of vocabulary of the target language can be achieved by using dictionaries which are considered as road maps for learning any target foreign language. Wang (2007) indicated that "dictionaries for a foreign language learner are just maps in a tourist's hand. A language learner has to know how to use a dictionary" (p. 15).

Wright (1998) referred to the importance of dictionary use indicating that it is the least-cost learning resource (Wright, 1998, p. 5). Being this, this learning tool is very important; no one can ignore or deny its vital role in language learning and acquisition. Thus, this study will be conducted to identify the practices and perceptions of Saudi EFL learners when using their dictionaries through answering the four research investigative questions which will guide this study.

\subsection{Objectives of the Study}

This study seeks to explore the following objectives:

1) To discover the difficulties that Saudi learners of English encounter while using their dictionaries

2) To discover the uses of dictionaries by Saudi learners of English

3) To discover the most preferred dictionary type for Saudi learners of English

4) To identify the amount of training that Saudi learners of English received while using their dictionaries

5) To identify the importance of training in dictionary use from the Saudi EFL students' perceptions.

\subsection{Research Questions}

The present study attempts to answer the following questions:

1) What type of dictionaries do the Saudi EFL students prefer to use frequently?

2) For what purposes do Saudi EFL students use their dictionaries?

3) What difficulties do Saudi learners face while using dictionaries?

4) Did the Saudi learners of English receive any form of training on the use of the dictionary and how did they find training from their perceptions? 


\subsection{Definition of Terms Used in the Study}

A dictionary: A book with a collection of words limited to an alphabetical order of the words that gives various kinds of information about the target words.

Printed Dictionaries: Dictionaries that are shaped on paper or another material using a machine.

Electronic Dictionaries: Dictionaries which include information in digital form and can be accessed by electronic media.

Bilingual dictionary: A book which includes words which are ordered alphabetically in one language to help the user to translate words or phrases into their equivalents in the other language.

Monolingual dictionary: A book which includes words within one language giving the meanings and other types of data of these word items.

\section{Literature Review}

Many studies conducted in different parts of the world investigate dictionary users and uses. The beginning of fundamental research into dictionaries use and their users goes back more than half century when Barnhart started his study in this field, specifically in 1962. Since that date lexicographers and researchers in different parts of the world have realised the urgent need to make further investigations in the dictionary field from different angles, to discover various findings in this regard which could make clear contributions in the knowledge which has now become an independent discipline. The studies that investigated in this field were various and in the different forms of Master's dissertations, Doctoral theses, articles, and books etc. These studies cannot all be collected and reviewed within this limited paper. Béjoint (1981) comments that "it is difficult to keep track of all of them". This paper investigates some practices followed by Saudi learners focusing on several areas such as their difficulties with dictionary use purposes, their preferred types of dictionaries, the information they search for in the dictionaries and the sort of training received by learners of English throughout their study for English until prior to postgraduate studies at the level of Master and Doctorate. The literature review in this paper will be divided into sections according to the issues which the study investigates based on the four guided questions stated in the first section .

\subsection{The Studies of Dictionary Use with Language Learners}

Bejoint (1981) conducted a study on more than 100 French students studying at the University of Lyon. The study produced several findings concerning dictionary use among French learners indicating that meaning was the main goal with a percentage exceeding $85 \%$; followed by grammar synonyms with a percentage exceeding half the students; spelling and pronunciation came next with $25 \%$ and lastly etymology with a limited use of dictionary for this goal of only $5 \%$ of the learners. Hartman (1983) indicated that translation was the main 
purpose for dictionary use among students as about $90 \%$ of the students used their dictionaries for this purpose, followed by reading with $83 \%$ of the students using their dictionaries for this purpose. The percentage for writing purposes was $74 \%$, while listening and speaking were rated as the lowest- rank activity among students with a percentage not exceeding $20 \%$.

Kipfer (1987) referred to the purposes of dictionary use among American students at high school indicating that they use their dictionaries mainly for spelling and meaning. Quirk (1973) referred to the purposes of dictionary use among English students at the University of London, indicating that the meaning followed by synonyms and antonyms were rated the main purposes of dictionary use by EFL learners, while pronunciation, grammar and etymology rated the least used types of information in dictionary use for the students. Elbadry (1990) conducted a study and it was clear through her findings on the uses of dictionaries that the main purpose of dictionary use among her participants was meaning followed by spelling and synonyms. This means that most of the studies agreed that the main purpose of using dictionaries was finding the meaning of new words of the target language (e.g. Arabic and English).

\subsection{The Studies of Problems in Dictionary Use among Language Learners}

Al-khub (1997) conducted a study on a number of students studying in Yarmouk University in the department of English language. The study discovered that the students suffered from three main problems when they used their dictionaries which were the spelling of words, the confusion of information used in the dictionary, and the insufficiency of the illustrations of the examples specified in their dictionaries. Hartman (1999) conducted a study on dictionary use on the students studying in the University of Exeter discovering the highest percentage of the students indicated that the information included within the dictionary was not sufficient, followed by different percentages of the students who referred to other difficulties such as not reading the instructions of dictionary use and lack of dictionary use. Ramos (2005) conducted her study on dictionary use among Spanish University students indicating that the main problem of her students was the difficulty of finding the words they were searching for. Alharbi (2012) conducted his study on 77 students in the preparatory year at the College of Applied Health Science of Qassim University in Saudi Arabia. Alharbi discovered through his study that Saudi learners of English suffer from a lack of efficient experience to deal with dictionaries.

\subsection{Studies of Dictionary Type Preferred by EFL Learners}

Today, dictionaries have undergone remarkable expansion and taken new forms and shapes. The use of these types by foreign language learners depends on several criteria and there are advantages and disadvantages for each of them. Many studies have been conducted cross the world investigating the most preferred dictionary type by EFL learners. Li (1998) conducted a study on Chinese learners of English. The study referred to the preferred type of dictionary by the Chinese learners, indicating that Chinese learners preferred using the bilingual dictionary over other types. However, Diab (1990) conducted empirical investigation on EFL learners and dictionary use discovering that the learners preferred using monolingual 
dictionaries over bilingual dictionaries. Iqbal (1987) conducted a study on advanced Pakistani learners of English. The study focused mainly on discovering how the advanced learners deal with their bilingual and monolingual dictionaries. Iqbal's study discovered that the students used the bilingual dictionaries more effectively because most of the students consider it more useful in explaining the meaning of the words.

\subsection{The Role of Training in Dictionary Use among EFL Learners}

Many studies conducted in this area confirm the important role played by training to prepare EFL learners to deal effectively with their dictionaries. Chi (2003) conducted a study on students' behaviours and choices when using dictionaries. Chi's study demonstrated dictionary use exploring whether training in dictionary use for students is important in enhancing the learners' experience in the knowledge and skills required to use English learners' dictionaries and solve some lexical complications. Wang (2007) conducted a study to study to investigate the importance of training in dictionary use. The study's findings demonstrated the importance of training in dictionary use thereby reducing the problems of use among EFL learners. Alajmi (1992) conducted a study on Kuwaiti EFL learners. Alemi's study stressed the importance of training on dictionaries' use. The study's findings indicated that most of the participants found that the training is necessary and stressed their need for training, although half of them claimed they received some sort of instruction in dictionary use.

\section{Research Method}

\subsection{Subjects}

The participants of the study were 20 Saudi male and female postgraduate students from different departments of the University of Salford, UK. They were selected randomly, subject to willingness to participate in the current study. All the Saudi students who participated in the present study were holders of the Saudi government scholarship to study in the University of Salford, UK.

Table 1. Subjects

\begin{tabular}{|l|l|l|l|l|}
\hline \multirow{2}{*}{$\begin{array}{l}\text { Gender } \\
\text { (males and females) }\end{array}$} & \multicolumn{2}{|l|}{ Academic level } & \multirow{2}{*}{ Total } \\
\cline { 2 - 4 } & MA & PhD & \\
\hline \multirow{2}{*}{ Gender } & Female & 6 & 2 & 8 \\
\cline { 2 - 5 } & Male & 10 & 2 & 12 \\
\hline Total & 16 & 4 & 20 \\
\hline
\end{tabular}




\subsection{Instruments}

The instruments that were used for collecting data were a questionnaire and interview. The researcher designed the questionnaire items carefully based on several previous studies e.g. Alharbi (2012) and Alowaimer (2010) to suit the population of the study and to provide the required information that could help him to answer the RQs reported in the current study. Interviews were conducted with a smaller number of the participants in the questionnaire. The instruments are detailed individually in the following sub-sections.

\subsubsection{Questionnaire}

The construction of the questionnaire was not an easy task. However, previous studies paved the way for the researcher to greatly benefit from these studies to construct his questionnaire (e.g. Hatherall, 1984; Kharma, 1985; Diab, 1990; Battenburg, 1991; Li, 1998;). The questionnaire was divided into a number of sections to guarantee that it answers the four research questions and consequently meets the research objectives. The first section was related to the type of dictionary preferred by Saudi learners. The second section was related to the purposes of the students' use of their dictionaries. The third section was related to the problems that Saudi students face when they use their dictionaries. The fourth section was related to the research question which investigates the amount of the training received by Saudi learners of English. The students were given some open questions in the questionnaire.

The answers of the participants to these questions of the first three sections (A, B and C) as labelled in the questionnaire are recorded on a five-point Likert scale which contained five choices for the sections $\mathrm{A}, \mathrm{B}$ and $\mathrm{C}$ of the questionnaire: 1 never; 2 rarely; 3 sometimes; 4 often; 5 always.

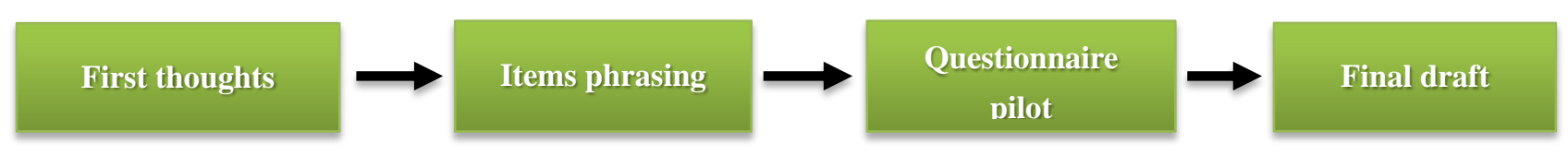

Figure 1. Stages of questionnaire development

\subsubsection{Semi-structured interview}

Interviews were the second research instrument used in the study. The researcher in this study used interviews after the questionnaire to obtain more details about the students' preferences, perceptions and their experiences which cannot be given through quantitative methods. The researcher, through his interviews with the participants directed a number of the questions. Most of these questions directed to the participants were about the problems of dictionaries, types of dictionaries they prefer to use frequently as mentioned in the questionnaire. The interview questions also covered training in dictionary use and how much training they received and their perceptions towards these issues which directly answer the research question no 4 of this paper. The researcher conducted all the interviews in the Arabic language to avoid L2 problems. Mackey \& Grass (2005) confirmed this matter indicating that "interview can be also conducted in the learners' L1, thus removing concerns about the 
proficiency of the learner impacting the quality and quantity of the data provided" (p.174). The number of participants in the interviews was only five and determined by their choice and willingness to participate. Some excerpts of the interviews with the interviewees are included in the section of discussion and results to support the results obtained from the questionnaire.

\subsection{Procedures}

The present study was conducted on Saudi postgraduate students who were studying in the University of Salford by using a questionnaire followed by smaller sets of interviews. The researcher started by distributing the questionnaires individually for all the participants who agreed to take part in the study. This process took place in different locations both inside and outside the University of Salford, and it took about three weeks for the questionnaires to be answered fully and then returned to the researcher. For the purpose of supporting data obtained from the questionnaire, the researcher used interviews to obtain more details. Denzion and Lincoln (2000) stated that the researcher can uncover in-depth and otherwise unobservable details regarding people's performance and thinking by accessing them directly through face-to-face interviews between the researcher and the participants. After completion of construction of the questionnaire in full, the questionnaire was piloted on a number of participants. After the researcher made sure of the consistency of questionnaire items with the research objectives, he started distributing the questionnaire individually. It took about two weeks for the questionnaires to be fully completed and returned. After compiling the quantitative data from the questionnaire, the researcher conducted interviews with some respondents of the questionnaire who agreed to participate in the interviews voluntarily.

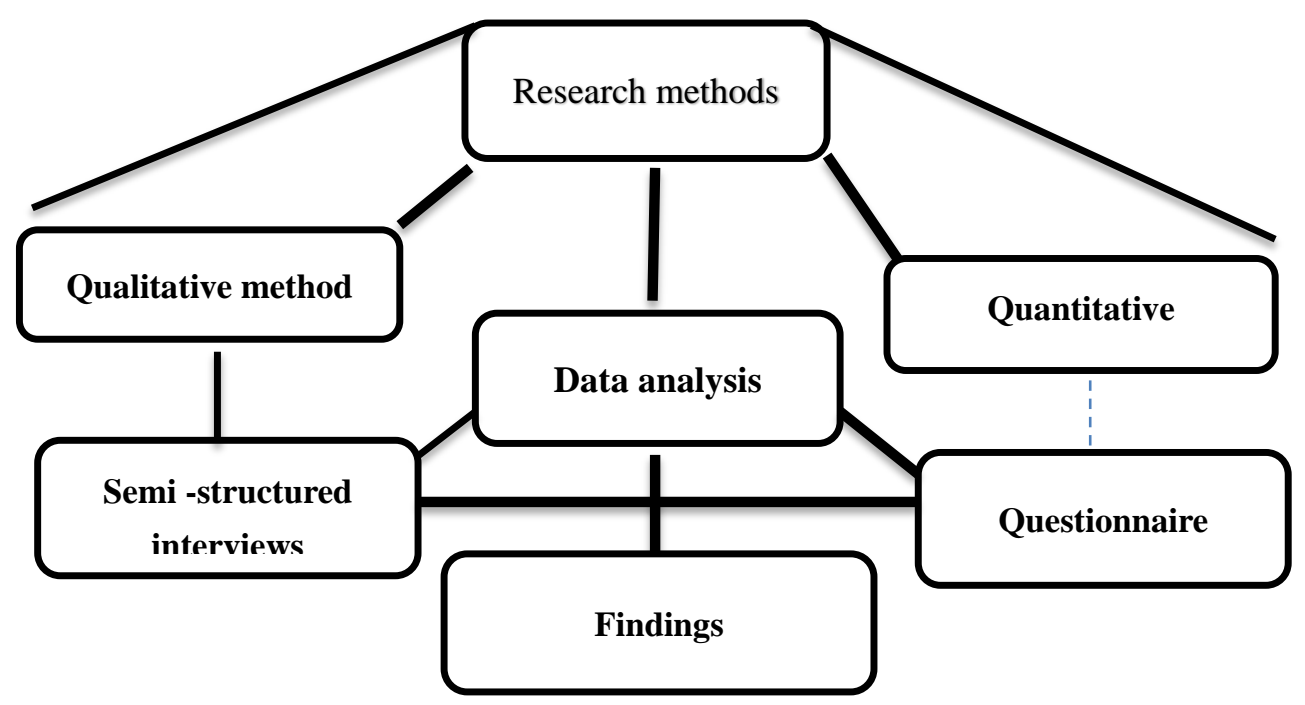

Figure 2. The process of research diagram

\subsection{Data Analysis Procedure}

The study adopted two research methods for collection data. The first was a quantitative method using the questionnaire and the second one was a qualitative method with the 
assistance of interviews. The findings which were obtained from the quantitative questionnaire will be determined for three research questions relating to dictionary problems the Saudi learners face, the type of dictionary the Saudi EFL learners frequently use and the purposes for which the Saudi learners use their dictionaries based on their responses in the questionnaire. The results of these questions will be analysed depending on the answers of the students as they are recorded in the questionnaire from 1 for 'never' to 5 for 'always'. The results of the study will be given clearly using tables to indicate the students' answers in the results section of this study. Small excerpts from the interviews with students will be added in some cases to support the answers obtained from the questionnaire to answer the research questions more appropriately.

\section{Results and Discussion}

In this section, the data will be presented, analysed and discussed. The research questions will be presented one by one, and each question will be answered based on the findings of the study which are relevant to it.

\subsection{What Type of Dictionaries Do the Saudi EFL Students Use Frequently?}

The students who participated in the study answered the question relating to the type of dictionary they use while learning the English language. Most of the answers of the respondents supported using an Arabic-English bilingual dictionary over other types. 16 students answered that they prefer using the Arabic- English bilingual dictionary, while only five students supported using the monolingual dictionary. In terms of dictionary format whether electronic or paper, the students through their responses in the questionnaire supported the paper dictionary over the electronic one, as 14 of the respondents answered that they use the paper version frequently as they answered with 'always', against only three respondents who answered with 'always' for the electronic version. To obtain more detail about the preference of the students for the bilingual dictionary in terms of content and the paper dictionary in terms of format, the researcher conducted some interviews with some students to gain deeper sight into their preferences, perceptions, and experiences. Moreover, some of respondents through the open questions and the sets of the interviews named the Arabic -English Oxford Dictionary as the best and the most preferred choice among Saudi EFL learners.

The researcher discovered that the Saudi learners preferred the bilingual dictionary for several considerations as they referred to them in the interviews. These considerations indicated that the bilingual dictionary is easy to use and the use of native language in it was an important factor as it could facilitate the method of learning effectively, while all the interviewees confirmed their preference of paper over electronic because it is more comprehensive with more illustrative details. Some studies in the Saudi context and EFL context in general, support this result given by the respondents. Al-Smael (2000) showed through his study on the Saudi EFL learners of Qassim university that the bilingual dictionary was more widespread than the monolingual dictionary among his Saudi undergraduate English major students. 
Table 2. Types of dictionary used

\begin{tabular}{|l|l|l|l|l|l|}
\hline The types of dictionary used & $\begin{array}{l}\text { Never } \\
(1)\end{array}$ & $\begin{array}{l}\text { Rarely } \\
(2)\end{array}$ & $\begin{array}{l}\text { Sometimes } \\
(3)\end{array}$ & $\begin{array}{l}\text { Often } \\
(4)\end{array}$ & $\begin{array}{l}\text { Always } \\
(5)\end{array}$ \\
\hline $\begin{array}{l}\text { I prefer to use paper } \\
\text { dictionaries. }\end{array}$ & 2 & 1 & 1 & 2 & 14 \\
\hline $\begin{array}{l}\text { I prefer to use electronic } \\
\text { dictionaries. }\end{array}$ & 2 & 7 & 6 & 2 & 3 \\
\hline $\begin{array}{l}\text { I prefer to use Arabic-English } \\
\text { bilingual dictionaries. }\end{array}$ & 0 & 1 & 1 & 2 & 16 \\
\hline $\begin{array}{l}\text { I prefer to use } \\
\text { English-English monolingual } \\
\text { dictionaries }\end{array}$ & 8 & 4 & 2 & 1 & 5 \\
\hline
\end{tabular}

\section{Excerpts from interviews}

$\boldsymbol{R}:$ Why do you prefer bilingual dictionary more than other types?

S1: I prefer it, because it is easy to use it in comparison with other types such as monolingual dictionary.

S2: I prefer it because the native language used in the dictionary can help me quickly find the meaning I search for

S3: I prefer the paper bilingual dictionary over the electronic dictionary because it is easy in usage and more comprehensive.

$\boldsymbol{R}:$ Which do you prefer electronic or paper dictionary in your study?

S4: I prefer paper over electronic, because it has more comprehensive information which can give me more illustrations which are not found in the electronic dictionary.

S5: I prefer the paper dictionary (although I use the electronic one as well) because it has more information than electronic one. Additionally, the paper dictionary has several illustrative examples of the usage of words in the appropriate place.

\subsection{For What Purposes Do Saudi EFL Students Use Their Dictionaries?}

According to the answers of the participants in the questionnaire the study discovered that about $95 \%$ of the Saudi students used their dictionaries for searching for the Arabic meaning of the English word followed by $80 \%$ who check pronunciation of the words. 19 of the total of 20 students who participated in the study answered with the choice of 'always', which is one of the choices of the five-point Likert scale used in the questionnaire and one responded with 'often'. The second purpose among the students was pronunciation of vocabulary with sixteen respondents answering with 'always' and three students with 'often' This high percentage of the choices of the purposes of uses of their dictionaries is consistent with most 
other studies which confirms this finding such as Bejoint (1981) who confirmed that approximately $90 \%$ of his students used their dictionaries for the purpose of searching for meaning. Additionally, Diab and Hamdan (1999) discovered through their study on Jordanian undergraduates that the most of the participants used their dictionaries for both meaning and pronunciation. Fan (2000) also discovered that his Chinese students used their dictionaries mainly for checking the meaning of unfamiliar words.

Table 3. The frequency of dictionary uses according to the participant responses

\begin{tabular}{|c|c|c|c|c|c|}
\hline Uses of dictionaries by Saudi learners & $\begin{array}{l}\text { Never } \\
\text { (1) }\end{array}$ & $\begin{array}{l}\text { Rarely } \\
\text { (2) }\end{array}$ & $\begin{array}{l}\text { Sometimes } \\
\text { (3) }\end{array}$ & $\begin{array}{l}\text { Often } \\
\text { (4) }\end{array}$ & $\begin{array}{l}\text { Always } \\
\text { (5) }\end{array}$ \\
\hline $\begin{array}{l}\text { I use my dictionary to search for the } \\
\text { Arabic meaning of the English word }\end{array}$ & 0 & 0 & 0 & 1 & 19 \\
\hline $\begin{array}{l}\text { I use my dictionary to check the spelling } \\
\text { of the English equivalents. }\end{array}$ & 0 & 2 & 3 & 5 & 10 \\
\hline $\begin{array}{l}\text { I use my dictionary to check the } \\
\text { illustrative examples }\end{array}$ & 2 & 4 & 5 & 4 & 5 \\
\hline $\begin{array}{l}\text { I use my dictionary to identify the } \\
\text { collocations used }\end{array}$ & 3 & 4 & 7 & 3 & 3 \\
\hline I use my dictionary to check the grammar & 3 & 5 & 5 & 1 & 6 \\
\hline $\begin{array}{l}\text { I use my dictionary to check the parts of } \\
\text { speech of words }\end{array}$ & 1 & 4 & 8 & 5 & 2 \\
\hline $\begin{array}{l}\text { I use my dictionary to check synonyms } \\
\text { and antonyms of words }\end{array}$ & 1 & 1 & 6 & 5 & 7 \\
\hline $\begin{array}{l}\text { I use my dictionary to check the } \\
\text { pronunciation of the vocabulary used }\end{array}$ & 0 & 0 & 1 & 3 & 16 \\
\hline
\end{tabular}

\subsection{What Difficulties Do Saudi Learners of English Encounter while Using Their} Dictionaries?

The questionnaire included a list of problems and the respondents were asked to refer to the frequency of these problems for them when they attempt to use their dictionaries. The responses given were graded according to the five-point Likert scale which was ranging between 'never' and 'always' as given in the questionnaire. The list of problems included relating the difficulty of finding the target words, difficulty in understanding illustrations of the given examples in the dictionary, the entries, the grammar used in the dictionaries etc. The students answered the question of problems of dictionaries' use by indicating a number of problems that they encounter when they use their dictionaries. However, three problems facing them when using their dictionaries were most frequently mentioned, namely "it is difficult to understand the phonetic symbols which refer to the pronunciation of the word", "it is not easy to find the correct word I search for", and "the illustrations given in the dictionary are not sufficient". 
The students suffer most from the phonetic symbols given in the dictionary and finding the correct word more than other problems. More than three-quarters of the student respondents stated that these problems face them as frequent problems with a percentage of $80 \%$ for the problem of understanding phonetic system symbols given in dictionary followed $75 \%$ with the problem of finding the intended target words correctly, and lastly the problem which was rated by students as the third most frequent problem was insufficiency of illustrations used in the dictionary for which thirteen students answered with 'always' corresponding to $65 \%$ (see Table 4.3). The researcher conducted some interviews to understand the nature of these problems and get more information in order to have deeper insight in this issue. The students confirmed that they do not understand the symbols used in the dictionary to pronounce the

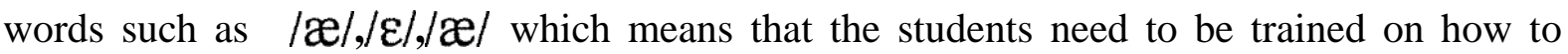
benefit more from this dictionary. Moreover, the students were asked about the second problem they face frequently while using their dictionary confirming that the way of indexing the dictionary sometime leads them astray and consequently they find it difficult to reach the correct words.

\section{Excerpts from interviews}

$\boldsymbol{R}$ : Do you think that phonetic symbols used in your dictionary should be considered a serious problem as you rated it?

S2: For me this problem makes me unable to understand the real pronunciation symbols as since I studied English language, I did not deal with these mysterious symbols such as [0], [ð], [J], [d3], [3]. How can learners understand these symbols if they do not have appropriate pictures about them?

$\boldsymbol{R}$ : Do you support that EFL learners should receive practical sessions to avoid these problems you state such as the problem of pronunciation symbols and problems of shortage of illustrations in some contents of dictionary?

$S:$ Of course, training is the best way of learning how to use dictionaries very well. I am hopeful that training in dictionary use receives significant attention; sometimes I feel that dictionary use is boring because I cannot access the correct word; I cannot pronounce some words due to the mysterious symbols.

Table 4. Frequency of dictionary use problems

\begin{tabular}{|l|l|l|l|l|l|}
\hline The problems of dictionary use & $\begin{array}{l}\text { Never } \\
(1)\end{array}$ & $\begin{array}{l}\text { Rarely } \\
(2)\end{array}$ & $\begin{array}{l}\text { Sometimes } \\
(3)\end{array}$ & $\begin{array}{l}\text { Often } \\
(4)\end{array}$ & $\begin{array}{l}\text { Always } \\
(5)\end{array}$ \\
\hline I cannot understand the definition well & 2 & 3 & 8 & 4 & 3 \\
\hline $\begin{array}{l}\text { The examples given in the } \\
\text { dictionaries are not clear }\end{array}$ & 0 & 6 & 6 & 1 & 7 \\
\hline $\begin{array}{l}\text { The directions in the dictionary are } \\
\text { not clear }\end{array}$ & 2 & 7 & 6 & 4 & 1 \\
\hline $\begin{array}{l}\text { The illustration given in the } \\
\text { dictionary are not sufficient }\end{array}$ & 1 & 1 & 2 & 3 & 13 \\
\hline The information given in the & 0 & 1 & 4 & 4 & 11 \\
\hline
\end{tabular}




\begin{tabular}{|l|l|l|l|l|l|}
\hline $\begin{array}{l}\text { dictionary is not enough to give me } \\
\text { all I need }\end{array}$ & & & & \\
\hline $\begin{array}{l}\text { It is not easy to find the correct word I } \\
\text { search for }\end{array}$ & 0 & 0 & 3 & 2 & 15 \\
\hline $\begin{array}{l}\text { It is difficult to understand the } \\
\text { phonetic symbols which refer to the } \\
\text { pronunciation of word }\end{array}$ & 0 & 1 & 1 & 2 & 16 \\
\hline
\end{tabular}

Did the Saudi students receive any form of training on dictionary use and how did they find training from their perception?

A large proportion of the Saudi students who participated in this study answered the question which asked them if they received any form of training on dictionaries use since they started learning English language with 'no'. Seventeen of the respondents confirmed that they did not receive any form of training in dictionary use against only three respondents who referred to receiving training as given in Figure 4.1. Many other studies in the Arab and Saudi context specifically and EFL context in general agreed with this result albeit with a difference in percentages, such as Alharbi (2012) who conducted his study on 77 students of Qassim University in Saudi Arabia. Alharbi's findings referred to the importance of the role of training in dictionary use indicating that training can equip the students with the required skills which help them to deal with their dictionaries effectively.

Moreover, Alowaimer (2010) through his empirical study on Saudi university learners of English referred to some cases of the failure of students in dictionary use attributing that to lack of dictionary use. Thus, the importance of giving practical training in dictionary use was clear from the students' perceptions when they were interviewed with the researcher, as all the interviewees agreed that training in dictionary use is very important. Additionally, all the students would hope that English language teaching syllabuses allocate part of their contents to provide practical training in dictionary use in order for the students to acquire the required skills to benefit from the efficient use of dictionaries. All the interviewees expressed their disappointment over the neglection of training in dictionary use and they consider it the lost treasure which cannot be discovered without actual training in how to use it appropriately according to their description. Many studies have asserted the importance of training in helping students to make effective use of dictionary, such as Alajmi's study (1992), which he conducted on Kuwait EFL learners to discover, in part of his study, the perceptions of the Kuwaiti learners toward the importance of training of learners in dictionary use indicating that half of students confirmed the importance of training in dictionary use.

Excerpts from interviews:

$\boldsymbol{R}$ : Do you believe that training in dictionary use is important in order to make good use of our dictionaries?

S1: Surely, training is very important as it helps pave the way in front of language learners or even other users who dictionary frequently, like translators, to be able to 
understand how they can they use their dictionaries.

R: Do you advise that training in dictionary use should be part of English language teaching curricula?

S4: Why not? I think this step will be a good step in the direction of learning English language teaching and learning. I think students who have a genuine desire to learn English need to use a dictionary, but sometimes do not use it in the right way, but if they are obliged to study how to use their dictionaries, through practical sessions within their curricula, the results will be positive.

R: Do you see that the training needs to be included as part of teaching English syllabuses?

S5: I think the negligence is clear in the way of dealing with dictionaries. I hope that the use of dictionaries is within our teaching English language. I am surprised that the designers of English syllabuses do not pay attention to the training in dictionary.

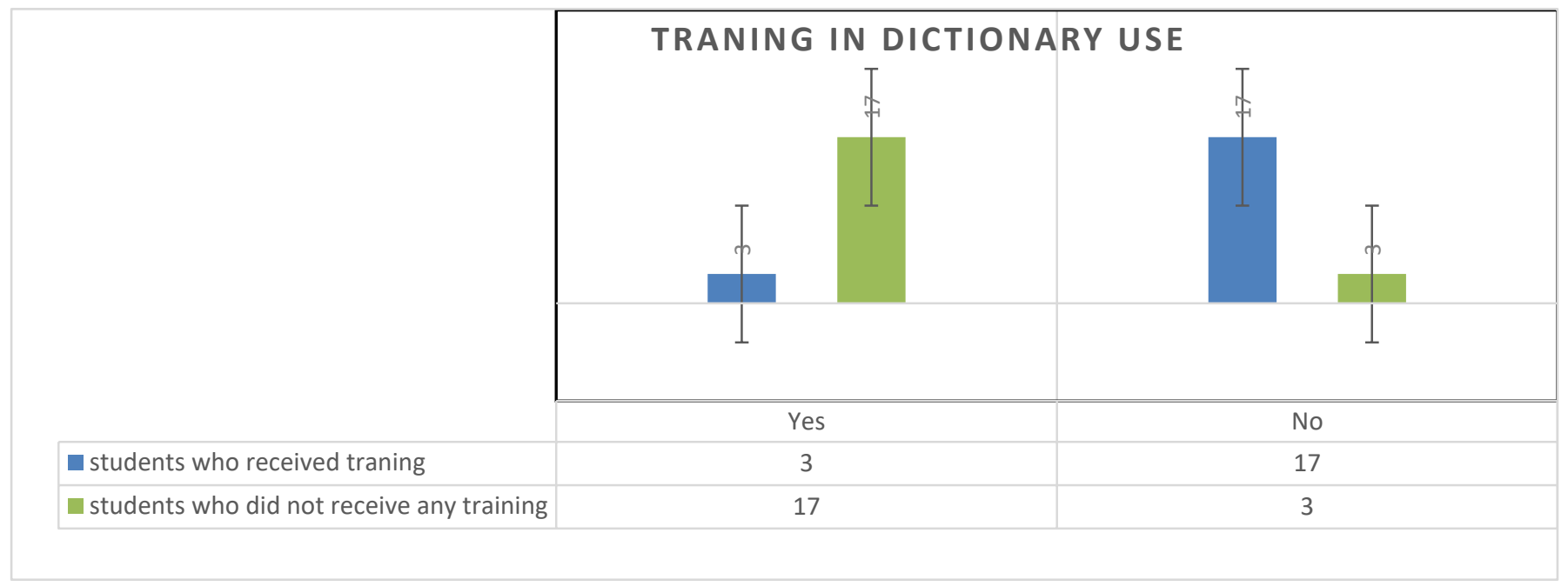

Figure 3. The number of students who received training in dictionary use

\section{Conclusion}

This study investigated the practices and behaviour of Saudi students towards the use of their dictionaries. For the purposes of quality and validity of findings, the study adopted a mixed research approach which included two main research methods namely questionnaire and interview. The study was guided by four research questions. The study, through analysis of the answers to the research questions, discovered many findings which were not far different from the previous studies conducted in this area thus confirming findings of some of these studies. The study discovered that most of the Saudi learners of English preferred using a bilingual dictionary in terms of content and a paper dictionary in terms of format.

The study discovered three main problems Saudi learners face while using their dictionaries. These were related as the difficulty of understanding the phonetic symbols of pronunciations 
of words, the difficulty of finding the target words correctly and insufficiency of illustrative examples used in the dictionary. Moreover, the study indicated that most of the students used their dictionaries for two main purposes which were searching for the meaning in Arabic of the English words in the first place followed by checking pronunciation as the second main purpose. The study concluded with emphasising the prime importance of training in dictionary use indicating where more than three quarters of the respondents on the questionnaire did not receive any form of training on dictionary use. The study indicated that most of the students were convinced that the training on dictionary use is very important and have positive attitudes toward including training in dictionary use within English language curricula.

\subsection{Limitations of the Study}

This study, like all studies, has limitations. These limitations and weaknesses were limited to the following points:

- The number of the participants was very few and consequently the results of this study cannot be generalised.

- The study did not include practical sessions of using dictionary among the students in order to make the researcher understand the practices and performance of the students with their dictionaries through observing what they do directly.

\subsection{Recommendations}

Based on the study's findings, the researcher provided the following recommendations:

- The learners of languages in general and English in particular should be aware of the importance of the dictionary and the valuable information that can be provided by this rich source.

- The learners of foreign languages should be given adequate training in dictionary use in order to make use of the dictionary contents effectively.

- The training in dictionary use should be included within English language teaching syllabuses in order for students to realise how to deal with their dictionaries.

- The English language and foreign languages departments in the Saudi universities are advised to include practical sessions of the English language teaching for the students majoring in English language in order to make good use of dictionary efficiently. Moreover, they need to include within their teaching plans independent practical courses on dictionary use for the most important tool of foreign language called for example Dictionary Skills Instruction or Practical Sessions in Dictionary Use.

- Researchers in this field are advised to investigate in this area with larger samples in order for results to be generalised and expand their researches in this field to include various angles. 


\section{I Macrothink}

- The publishers of dictionaries in the world need to revise the dictionaries provided annually in order to meet the needs of the dictionary users, specifically foreign language learners.

\section{References}

Al-Ajmi, H. (1992). The use of monolingual English and bilingual Arabic-English dictionaries in Kuwait: an experimental investigation into the dictionaries used and reference skills deployed by university students of arts and science. Ph.D. thesis. University of Leeds. Leeds.

Alharbi, B. (2012). An Investigating into dictionary use by Saudi EFL tertiary students. Unpublished $\mathrm{PhD}$ thesis, University of Exeter. United Kingdom.

Al-Khub, W. (1997). Dictionary-Related and Vocabulary Building Skills among English as a Foreign Language Learner in Yarmouk University. Unpublished MA Thesis, Yarmouk, Irbid, Jordan.

Alowaimer, S. (2010). An Empirical Study of Dictionary Use by Saudi EFL Learners at University Level with reference to Major and Gender. Unpublished PhD thesis, University of Salford. United Kingdom.

Al-Smael, F. I. (2000). A think-aloud protocols investigation of lexico-semantic problems and problem-solving strategies among trainee English-Arabic translators. Ph. D. Thesis, University of Durham

Battenburg, J. D. (1991), English Monolingual Learners' Dictionaries -A User- Oriented Study, Tübingen: Niemeyer.

Béjoint, H. (1981). The foreign student 's use of monolingual English dictionaries: a study of language needs and reference skills. Applied Linguistics, 2(3), 207-222.

Chi, A. (2003). An empirical study of the efficacy of integrating the teaching of dictionary use into a tertiary English curriculum in Hong Kong: Language Centre, Hong Kong University of Science, and Technology.

Denzin, N. K., \& Lincoln, Y. S. (2000). Introduction: The discipline and practice of qualitative research. In N. K. Denzin \& Y. S. Lincoln (Eds.), Handbook of qualitative research (2nd ed.) (pp. 1-28). Thousand Oaks, CA: SAGA Publication.

Diab, T. (1990). Pedagogical lexicography: a case study of Arab nurses as dictionary users. Tübingen: Niemeyer.

Diab, T., \& Hamdan, J. (1999). Interacting with words and dictionaries: The case of Jordanian EFL learners. International Journal of Lexicography, 12(4), 281.

El-Badry, N. 11. (1990). Bilingual dictionaries of English and Arabic for Arabic- speaking advanced learners of English, PhD. thesis, University of Exeter. 
Fan, M. Y. (2000). The dictionary look-up behaviour of Hong Kong students: A Large-scale survey. Educational Journal, 28(1), 123-138.

Hartmann, R. R. K. (1983). The bilingual learner 's dictionary and its uses. Multilingual Journal of Cross-Cultural and Interlanguage Communication, 2(4), 195-202.

Hatherall, G. (1984), Studying dictionary use: some findings and proposals. In R. Hartmann (ed.), Exeter' 83 Proceedings. Tübingen: Niemeyer, 183-189.

Kharma, N. N. (1985), Wanted: a brand-new type of learners' dictionary. Multilingual, 4, 85-90.

Kipfer, B. A. (1987). Dictionaries and the intermediate student: communicative needs and the development of user reference skills. Cowie (ed.), 44-54.

Li, L. (1998). A study of dictionary use by Chinese university learners of English for specific purposes. Ph.D. thesis. University of Exeter.

Mackey, A., \& Grass, S. (2005). Second language research: Methodology and design. Mahwah, NJ: Lawrence Erlbaum.

Quirk, R. (1973). The social impact of dictionaries in the UK. Annals of the New York Academy of Sciences, 211(1), 76-88.

Ramos, M. M. (2005). Research on dictionary use by trainee translators. Translation Journal, 9(2).

Wang, M. H. (2007). The effects of dictionary skills instruction on reading comprehension of junior high EFL students in Taiwan. Unpublished Master Thesis, National Sun Yat-sen University.

Wright, J. (1998). Dictionaries. Oxford: Oxford University Press.

\section{Copyright Disclaimer}

Copyright for this article is retained by the author(s), with first publication rights granted to the journal.

This is an open-access article distributed under the terms and conditions of the Creative Commons Attribution license (http://creativecommons.org/licenses/by/3.0/). 